\title{
Notas para un análisis de la poesía de Miguel Fernández
}

José Luis Fernández de la Torre

Una trayectoria poética como la de Miguel Fernández $z^{1}$ se conforma o construye desde una escritura heterodoxa (en el panorama poético coetáneo) y radical (sin concesiones, en su propia formulación); desde, y por, la nada de su ciudad natal (Melilla) y donde el trabajo del poeta en tanto conciencia colectiva necesariamente es, o se pretende, conciencia de ruptura, con el peligro de los limites, la crisis amenazante, la falta de comunicación, retoricismo... pero también con el conocimiento - inconsciente, valga la paradoja - de que hay que hacer de la poesía un acto de la existencia.

Cuando esta producción ha sido sometida al análisis, la perplejidad que provoca conduce a la mímesis, reiterativa de clisés o a la enumeración de datos y problemas. ${ }^{2}$ Con dos notas caracterizadoras: Poesía de la frontera-Poesía del

1. Jalonada por los siguientes títulos:

-Poesía completa (1958-1980), Madrid, Espasa-Calpe (Selecciones Austral, 109), 1983.

- Discurso sobre el páramo, Melilla, Ayuntamiento (Rusadir, 8), 1982.

- Historias de suicidas, Madrid, Libertarias, 1990.

- Secreto secretisimo, Madrid. Torre Manrique, 1990.

-Fuegos de la memoria, Sevilla, Fondo de Culura Andaluza, 1991.

-Laocoonte, Vélez Malaga, Ayuntamiento, 1991.

2. Es evidente que de los articulos-reseñas de las sucesivas publicaciones no se puede esperar rigor crítico y la parcialidad es dominante. Destacarían: M de Gracia Ifach, "Miguel Fernández: Credo de libertad" Insula, 119, 1959, p. 8. A. Abad, "La libertad torturada de Miguel Femández", Sur, 22 de Diciembre de 1979. J. Lupiañez, "Miguel Fernández: la vuelta a los orígenes", Nueva Estafeta, num. 19, 1980, pp. 88-89. J. L. Cano, "Miguel Fernandez, Sagrada materia", Puerto, 1, 1967. pp. 106-108. E. Miro, "Cronica de poesía", Insula, 245, 1967, p. 7. G. Díaz-Plaja, "Juicio final de Miguel Fernández", en Cien Libros españoles. Poesía y novela 1968-1970, Madrid, Anaya, 1971, pp. 157-160. J. Siles, "Juicio final de Miguel Femández", Las Provincias, 23 de Agosto de 1970. A. Domínguez Rey, “Monodía de Miguel Femández", Poesía Hispanica, 266, 1975, pp. 17. 19. A. López-Casanova, "Poética de Miguel Fernández", La Estafeta Literaria, 615, 1977, 2.877. 2.878. D. Santos, "Miguel Fernández y la Reencamacion en la palabra", Pueblo, 8 de Diciembre de 1978. L. de Luis, "Las flores de Paracelso", Ya, 5 de Abril de 1979. G. Camero, "La poesía de Miguel Fernández", Las Provincias, 26 de Octubre de 1975. E. Molina Campos, "Hacia una interpretación global de la poesía de Miguel Fernández", Hora de poesía, 8 1980, pp. 78-85.

Y, sobre todo, los dos libros de conjunto: F. Rincón, La poesía de Miguel Fernández, Valencia, Ed. Bello, 1978 y S. Wahnón, El irracionalismo en la poesía de Miguel Fernández, Granada, Antonio Ubago, 1983. 
aislamiento. Frontera porque se produce en una ciudad fronteriza (G. DrazPlaja) y "logicamente" esta lejanía se traspasa a su aislamiento cronologico, a su situación entre la segunda generación de postguerra y los novísimos (A. Domínguez Rey). ${ }^{3}$ De aquí que en Miguel Fernández los dogmas generacionales no sean operativos, a pesar incluso de $\mathrm{M}^{\mathbf{B}}$ Pilar Palomo y Domínguez Rey: La primera como coordinadora de la presentación en sociedad de lo que tímidamente se llamo Poetas del 60 (Zamora 1987) y en la que participaron, ademas de nuestro poeta, J. Benito de Lucas, A. García López, A. Hemández, D. J. Jiménez, M. Ríos Ruí, J. H. Tundidor; el segundo, con la publicación ya citada, en la que sitúa junto a los anteriores a R. Soto Vergés, J. Marco, F. Grande, C. Alvarez, J. Campal, A. Barasoain, C. Oroza, R. Defarges, J. Caro Romero y F. Ferrer Lerin.

Sin embargo, carece de sentido emprender la búsqueda del cumplimiento o incumplimiento del código, incluso inventar uno nuevo porque el resultado es desolador, el perseguir subjetivismos, estilismos, inoperancias, remodelaciones. La poesía de Miguel Fernández, su eficacia, está en la escritura, así se recupera la realidad, su realidad ante tanta castración diaria e institucionalizada, represión, marginación, servilismo. Solo así conseguiremos explicar esa heterodoxia y radicalismo que senalábamos más arriba, aunque estemos rozando el riesgo de lo innecesario o se pueda caer en otro despliegue constructivo tópico.

Pensemos por ejemplo, en su participación en las revistas de los años cuarenta-cincuenta y fundamentalmente en Melilla, con Manantial y la que él mismo elaboró y dirigió, Alcándara, con dos únicos números, cercenada por la censura. O en su papel de dinamizador cultural de su ciudad a través de la Junta de la Biblioteca Pública en estos años de postguerra.

En este repaso temporal, pensemos también que su primer libro Credo de libertad (1958) aparece en un marco histórico poético muy concreto, la llamada poesía social, aunque su titulo ya es suficientemente significativo: por el credo hacia la libertad o la inversa. Aparentemente dos difusas realidades se tematizan, lo social y lo religioso, elementos claramente instalados en el horizonte del momento, para construir la diferencia, autoafirmarse en ese marco externo conduce a la asepsia estética, a la atemporalidad y, por tanto, a un cierto simbolismo irracionalista. Se mueve en el mismo terreno o valores desde otra posición radicalmente corrosiva, con dos cristalizaciones: sed ("Dadme la sed", "os pido un vaso de sed")-pan ("El pan... nos cubre el cielo de la boca"); un libro que reparte "palabras de limosna que hielen el alma de los pobres" y concreta una primera poética en Con los ojos cerrados, donde se lee:

3. G. Díaz-Plaja, "Prólogo", en Miguel Fernández, Poesía completa..., Ibidem, pp. 17-38 y A. Dominguez Rey, Novema versus Povema. Pautas liricas del 60, Madrid, Torre Manrique, 1987. especialmente pp. 8-12. 
Hace tiempo que escribo sólo estas mentiras. Cuando leáis mis versos, creed que ya es inútil confiar en la voz de un poeta que canta.

Creed tan solamente en aquellas palabras que os venía diciendo cuando nunca os hablaba. (Mientras andamos lentos, mientras vamos bebiendo o cuando se tirita al compás de un mendigo, la vida es otra cosa; se transporta, se eleva perdida ya en su azul laberinto de dioses, sufrientes potestades, realidad de los seres que día a día nos dejan su polvillo gastado). Esto es irrefrenable y me pongo de espaldas, quise un día dejar de escribir estos versos y vivir con la vida todo lo que me otorga. Por eso yo os lo juro que estamos engañando. Todo es mentira. Creed al hombre solo.

La cita, extensa ciertamente, y el detenimiento en esta primera entrega se legitiman porque a partir de aquí el discurso no cambia sustancialmente y radicaliza su formulación en variantes. Asf, después de unos años de silencio, en 1966, aparece Sagrada materia. Externamente autobiografico con un fuerte componente religioso (el poema titulado Las Bienaventuranzas es ejemplificador) pero, sobre todo, expresamente cultural, donde irrumpen dos realidades artísticas: música y pintura. Estas "amadas sombras", estas realidades "encubridoras"4 inevitablemente sugieren uno de los tópicos más repetidos: su barroquismo, sin embargo, pensamos que el elemento dominante es estrictamente metafísico o fenomenológico; es la angustia de la afirmación del creador lo que esta implícito.

En Juicio final (1969) las constantes se mantienen con un refuerzo del culturalismo, de las sombras y lo lúdico. Su poesía, pues, producto histórico en tanto que se encierra o es consecuencia de una crisis real, efectiva. Desde Juan Ramón Jiménez, y no digamos con los poetas del 20 , la poesfa cada vez mas se encierra en sí misma, se despega o lo intenta -incluso con fenómenos como la poesía social一, se reduce y no tiene público; por eso mismo se vuelve, se pretende atemporal, en este sentido, universalista.

Monodia (1974), que posiblemente suponga un proceso muy acentuado de lirificación simbólica (poema Modulema) del tiempo y de la forma con su aparente sencillez, se mueve en la relación, tan básica, poeta/silencio interior.

4. En la formulación exacta de Arcadio López-Casanova, "enunciación encubridora", vid. A. López-Casanova y E. Alonso, Poesía y novela. Teorla, método de análisis y práctica textual, Valencia, Ed. Bello, 1982, p. 195 y ss. 
Proceso que tiene su continuidad e intensificación en Atentado celeste (1975), con su extremado cultismo y Eros y Anteros (1976) donde el erotismo (en soledad o compartido) no es más que apariencia lúdica, incluso con la utilización de un esquema clásico, el soneto.

Entretierras (1977) aparentemente insiste en lo autobiográfico o lo cercano: muerte de la madre, y en consecuencia, angustia, con un desprendimiento de juegos retóricos. Mas lo dominante y subyacente vuelve a ser la reflexión sobre la propia poética a partir de la muerte y la poesfa como consolación.

Un cierto interludio supone Flores de Paracelso (1979) con la intensificación de lo lúdico que se mantiene también en Del jazz y otros asedios (1980) aunque aqui aparece un texto fundamental:

Oh tú, el empecinado de arrogancia;

con la altiva mudez, ante la fiesta torpe y su ponzona, busca la soledad.

Entierra el paño

de los viles oficios

El incomunicado del escarnio, acércate hacia el borde.

Contempla asi tu tierra.

Salta al abismo de la mar gritando:

nadie recuerda ya las profecfas.

Es, sin duda, una de las composiciones mas explícitas, poesía que se encuadra en la crisis histórica de la poesía misma.

El libro que cierra su Poesía completa, Tablas lunares (1980), es a su vez un libro térmico que refuerza la unidad básica y significación de las posibilidades: cultismo extremo, ludicismo, elaboración, perfección que condiciona la dificultad extrema y externa.

En 1982 aparece Discurso sobre el páramo. (Suite de La Florida) donde Goya pero también Jovellanos, Feijoo, etc. son voces del propio poeta:

Y mira el circulo de apócrifos

quien crea e inventa; el más solo del mundo,

quien más amor posee pero que nunca compartirlo puede.

El yo, afirmado y consolidado, puede valerse de otros creadores como de elementos temáticos diversos, recursos formales,... porque sólo existe en la escritura de la crisis emblemática de la poesía y la palabra es, en este caso, la única realidad, secreta... posiblemente. Cuando lo cotidiano es efímero y mezquino solo queda la escritura-existencia o la inversa: 
Solos de gabinete con su botella de siempre bebida hasta la hez.

Que así es la soledad.

(En Del Jazz y otros asedios)

Soledad-vida/creación-poesía, constantes en su variables en la fenomenología poética de Miguel Fernández.

Tras unos años de silencio, en 1990 aparece sus Historias de suicidas (con un Pórtico de Pere Gimferrer) que nos sitúan ante el problema de los limites genéricos, dilucidar si los treinta personajes tratados - de ficción o realesson, por la técnica, ensayo, cuento, prosa poética... Una cuestión probablemente baladí, supérflua porque lo que interesa subrayar es la anomalía, lo irracional o ilógico de la muerte.

Ya en su primer libro publicado en 1958, Credo de libertad, había tratado el problema con Elegía para un suicida y, ahora, esta fascinación por la muerte adquiere la condición de un Requiém continuado y versatilizado en personajes como Petronio, Virginia Woolf, Larra, Marilyn Monroe, Cesare Pavese, Van Gogh, Malcom Lowry,... es decir, personajes reales o de ficción: Madame Bovary, Crisóstomo, Werther,... Y cada uno de ellos elaborados técnicamente por un punto de vista diferente: desde el monologo interior a la escena teatral pasando por la epístola, la lección magistral o el reportaje periodístico.

La repercusión en la prensa diaria del libro 5 exime de un detenimiento mayor. Tampoco es el lugar para el análisis de la autodestrucción o la impostura de la escritura, el ejercicio de lo vacio, el culturalismo convertido en "poética del instante" que sefiala Gimferrer en el Portico. La conclusion es que la literatura es lo único que importa o salva, pero situarse en los limites de la transgresion, en la inevitabilidad de la misma nos conduce a un campo problemático: a una cuestión ética.

La sucesion de muertes, la cadena de suicidios, ese pathos trágico es utilizado como una reafirmación de los propios valores, la ritualización conduce a la artificialidad de la retórica y a "saber-que-uno-no-sabe-de-que-está-hablando".

En el mismo año 1990 aparece Secreto secretisimo, libro que habra obtenido el Premio Tiflos del año anterior, una nueva tematización sobre el conocimiento y oficio poéticos y el problema de la palabra-escritura. Desde el primer poema Iniciación del vuelo el tema es claro: con él se inicia un nuevo libro, volar es escribir, aunque también

5. Luis de la Peña, "Suicidas literarios", El Independiente, 6 de Septiembre de 1990; Antonio Garrido, "El suicidio como creación", Sur, 27 de Octubre de 1990; Francisco Rincón, "Suicidas célebres", El Cerdanyola, Octubre de 1990; Antonio Enrique, "Miguel Fernández: Historias de suicidas", Córdoba, 17 de Enero de 1991; Arcadio López-Casanova, "Historias de suicidas", Diario 16, 31 de Enero de 1991. 
Morir, seguir volando, sin que nadie lo sepa

que has de obtener la vida; sacrificando mustios

saltos que se prendieran en aquellos tus dedos,

epitalamios fúnebres,

y argollas.

y escribir, por tanto, es perpetuarse, necesidad de (re)conocimiento. De aqui, la insistencia en La Mudez, Palabra, Eco, El más secreto pronunciar o las identificaciones de palabra y èl talismán o la recurrencia de las voces y las melodfas o el silencio (en Calladas estatuas), la sacralización del vuelo, etc., que dan lugar a un esencialismo escueto en el decir, por ejemplo, El dormido:

La brujería del dormido, ve lo soñado.

Mas habla en duermevela

y su lengua no dice lo ya visto,

aunque sí visto,

nunca dijera,

que fuera una falacia.

Esencialismo, brevedad (Distante, Sean las transparencias,...) que todavía combina con poemas más extensos como Respuestas del amor, Recordatorio o los interludios Piscina de Siloe, Tapices, etc.

Poemas que sobre todo suponen la autoasunción de la literariedad del discurso que algún critico llamó neo-romántico, siempre acicateados por los efectos de su propia fascinación aunque no esté en condiciones de comprender cabalmente, una nueva estetización que abarca desde Pájara Pinta a Degollación de los cuerpos que significativamente comienza: "Gustaba de mi canto solo yo". Una poética que se reconoce como modalidad constructiva:

No tengo mas oficio que estar solo, mirando la techumbre de mis nubes.

A veces, en el cielo veo pájaros, $y$ alguna vez un rayo que me alumbra

Esto es, como técnica del rapto para afinar el modo de un argumento; o bien se encapsula como un sistema de figuras que sirven para ornamentar el discurso como en Embeleso en lo negro:

Oh dama de misal

y coqueluche,

a la vez. 
Tus medias negras tan labradas

enredan tanto ojo por tus piemas,

que quien se labra siempre es la visión.

Una poética que muy especialmente se define en el texto que cierra el libro y al que da título:

\author{
Sin pedirte recado, \\ canté tanto secreto secretísimo \\ de nuestra comunión, \\ que mis ojos no quiero alzar siquiera \\ donde los tuyos tanto pestafiean \\ y $\tan$ hermosos y serenos vuelven, \\ que ese mirar es dulce \\ y perdona la afrenta \\ de no haberte mirado cual reliquia \\ de aquella vez que andabas \\ pintando alas a las mariposas, \\ dando al cervato leche \\ de tus pechos manantes de melaza.
}

Asi, la retórica rehabilitada del secreto tiende a fundirse con el otro, el ausente, no busca perfeccionar el repertorio de los tropos, sino el sentido, es decir, revelar el secreto de su constitución en un nuevo metadiscurso.

Esta interminable reflexión de autodestrucción por obra de la poesía tiene una nueva cristalización en Fuegos de la memoria (1991) en el que recoge poemas publicados en revistas o inéditos, de momentos a veces muy lejanos en el tiempo pero que se justifican por lo islámico que los unifica y la propia mirada.

La literariedad que configura este nuevo referente: lo musulmán con su plástica, folklore, vida indolente, la concepción del no-tiempo, el goce de los sentidos,... hace que no pueda escapar de la figuralidad, sus propios términos quedan atrapados dentro de las figuras que intentan describir. Porque no hay ni puede haber una tropologia de la tropologia. No hay en este sentido referente para un juego del lenguaje que no sea a su vez otro juego del lenguaje.

De esta forma, Miguel Fernández y su fascinación lo hace volver a la retórica, a asumir la propia retoricidad como el elemento más definitorio del lenguaje; y, junto a ello a asumir la impresión de que esa retoricidad es la faceta del lenguaje que no ha podido ni puede ser reducida a la logica (de nuevo, asi, 10 irracional en poemas como Castillo de Basbel, Cielos, Persecución, etc.) ni a la teoría del conocimiento (Llamando a la memoria, La vieja patria, Medina, etc.).

En efecto, la posibilidad de la interpretación gramatical del enunciado presupone que el lenguaje y el mundo constituyen ámbitos conmensurables, que la 
referencia no es una falacia. Como, por ejemplo, el poema titulado Qasida del fiel amor de Ben Al-Labbana de Denia, a Mutamid de Sevilla que comienza:
Ahora en Agmat, mi rey, cuando el potente Atlas avasalla con sus duras barrancas que ensombrecen tus predios, esta choza de cáñamo y estos huecos adobes que son ya tu palacio, donde la lluvia mansa da luz a la palmera y a sus dátiles huérfanos

Un extenso poema-canto ante la tumba de Mutamid en Agmat en el que el poeta, como el fidelísimo amigo-poeta del rey sevillano Ben Al-Labbana, reflexiona sobre lo efímero de la vida con un fuerte componente melancólico en el que se puede ser "dichoso en la belleza" y, a pesar de la muerte, "vencedor por siempre... entre mis lágrimas".

Esto es, lo que la poesfa viene a mitigar es la distancia del presente, el puente que descubre en realidad un nuevo abismo pero que está escondido o encerrado en cada texto o poema.

Laocoonte (1991) es su última publicación, por ahora. Se trata de un poema extenso con 25 estrofas en cuartetos endecasflabos que ya desde el título y las dos entradas: "Ante el cuadro Laocoonte, de Francisco Hemández" y "Basta con que la verdad y la expresión, lo feo de la Naturaleza, se transforme en lo bello del Arte", de Laocoonte, de Lessing nos señalan las claves de uno de los textos mas crípticos del poeta: acudir a la mitología para crear un propio universo mítico. Esto es, Laocoonte genera una simbologia a través de la cual trasciende la pintura, el cuadro del mismo título del pintor melillense, afincado en el pueblo de Málaga, Francisco Hemández, que provoca el poema. Trascendencia que conduce a sus preocupaciones estéticas para dejar manifiesta constancia de que la mitologfa es motivo de interés en sf misma.

No solo muestra-demuestra un referente cultural, un motivo recurrente en la tradición áurea por ejemplo, también sus conocimientos y sus propias recreaciones estéticas. Así, el texto aparece dividido en tres partes: la primera abarca desde el primer cuarteto al 15, la segunda desde el 16 al 20 y la tercera del 21 al 25. Este desequilibrio tripartito y progresivo sostiene la recreación personalísima del mito clásico, expresión del color en grupo, un referente lejano donde sus notas caracterizadoras solo se insinúan porque lo que interesa subrayar es la fugacidad del poder, la vida, su abrupto cesar y todo ello con un metaforismo extremo, un retoricismo esencial conformado por el endecasilabo y la estrofa tradicional y, sobre todo, la omnipresencia del dolor y su representación emblemática: "la culebra frutal", el áspid, las viboras del mito.

$\mathrm{Y}$ es que, como señalábamos, el tópico ut pictura poiesis en Lessing se formula:

"El primero que comparó la pintura y la poesfa fue un hombre de gusto refinado que sintio que las dos artes ejercían sobre él un efecto parecido. Se 
daba cuenta de que tanto la una como la otra ponen ante nosotros cosas ausentes como si fueran presentes, nos muestran la apariencia como si fueran realidades; ambas engañan y su engaño nos place". y en su Cartas sobre temas de la Antigüedad habra afirmado: "En el estudio de la Antiguiedad, a menudo es más honroso encontrar lo verosímil que lo verdadero..."6 Por eso no puede extrafiar que el poema que tratamos despliegue sus propios referentes al margen del mito y el cuadro de Hernández, y Laocoonte personifique no un sacerdote sacrlego sino un patriarca o poderoso que contempla desde la cumbre o risco-túmulo, donde se cumple su muerte, un valle con un bestiario y paisaje cuasipastoril:

Del grito agrimensor desde la cumbre dirigiendo las recuas y los riesgos; y el toro enlodazado en el alumbre de errantes ojos que se miran ciegos.

El texto va construyendo asf su propia verosimilitud con cedros, zonas umbrias, agua, tórtolas, alacranes, lechones, lebreles, etc. o imágenes de muerte animal:

Si el desplume voraz fuese alimento de alas fatuas que las plumas nievan.

Ya copos solidarios por el viento, vedejas albas que plumones lluevan.

El ave depredadora que acaba con la inocencia de la blancura (¿paloma? ¿gavilán?) y el esencialismo metaforizador con personificaciones inesperadas que conforman este paisaje premonitorio de dolor y muerte. Es un paraíso, un locus aemenus al revés, es paralso-infiemo, es imagen adánica al revés:

Oh trinidad, Laocoonte, el torso ardido,

la culebra frutal, la elevadora

que asedia el patrimonio en tí yacido.

Trepante en sí, la víbora se dora.

Esta primera parte se cierra con un cuarteto donde el áspid es ro, la trinidad, es decir, Laocoonte y sus hijos, es de asfixia y la imagen fluvial permite el deslumbramiento de los peces.

Trazado el marco, los cinco cuartetos que forman la segunda parte suponen

6. Laocoonte o Sobre las fonteras de la poesia y la pintura. Ed. Eustaquio Barjau, Madrid, Editora Nacional, 1977, pp. 37 y 11 respectivamente. 
un avance hacia la muerte exasperante, el reptil y su veneno cumplen con su inevitable misión viscosa, repugnante que permite anunciar:

Moriré como un mar que nunca acaba

de sepultar su sol en las cadenas.

Cingúlame la víbora. Es mi llaga

el ahorcado cordon de mis cadenas.

$Y$ así se llega al final intensificado por los recursos metafóricos o retóricos desplegados: la repugnancia del reptil es igualada o identificada con lo porcino, la soledad de la muerte es subrayada por lo elementos naturales ("breñales de angostura", "viña a tu soledad", "jara en el monte"), el poder es soledad ("Portas la herencia solo", "Hondero estás de gente que se sierva"), incluso el bestiario es indicativo de la inevitabilidad de muerte (caracol que en su insignificancia "roma la hierba") para concluir:

La vibora del mundo está en su pena

Cuida ya tus silencios con un tajo.

Cabeza volteada por la arena.

Circo redento. Círculo hacia abajo.

Donde aquella lentitud exasperante es precipitación y confirmación de la recreación del mito y el tópico ut pictura poiesis...

Decía Don Diego Hurtado de Mendoza: "pierdo la razón mas no el sentido". Así construye Miguel Fernández el sentido de su obra, en esta constante y magistral oposición de soledad-vida-muertelcreación-poesía-escritura. 